The authors modestly say that they have said the first word on the subject and not the last. In the limitations which they have set themselves they have achieved a remarkable synthesis from the almost unexplored ground common to economic history and chemical technology. In manuscript the work was awarded the ISenior Hume-Brown Prize by the University of Edinburgh; and, if the book is mainly devoted to the work of industrial scientists of North Britain, we can concede with the authors that "a galaxy of Scotsmen gave scientific direction to the Industrial Revolution, particularly in its hitherto neglected non-mechanical aspects". The writers have found inspiration in Lewis Mumford's "Technics and Civilisation" and have adopted his terminology, extended from that of Patrick Geddes--"one can divide the development of the machine and the machine civilization into three successive but overlapping and interpenetrating phases: eotechnic, palæotechnic and neotechnic. Speaking in terms of power and characteristic materials, the eotechnic phase is a water and wood complex, the palæotechnic phase is a coal and iron complex and the neotechnic phase is an electricity and alloy complex". The authors do not go beyond the first two phases.

The chief subjects in the book are minerals and manufacturing processes, the economy of common salt, ashes and kelp, the palæotechnic transition and vitriol in the Industrial Revolution. The chemical industry is the most polygamous of all industries, and Justus Liebig's famous bon mot of 1843, "We may fairly judge of the commercial prosperity of a country from the amount of sulphuric acid which it consumes", comes with even more point to-day. There are sections on balloons, bleaching and dyeing (before the days of Perkin), calico printing, mordants and mackintoshes. The considerable quantity of ammonia which was required for some of these processes was obtained from urine (a common practice being the dilution of this personally produced product by the canny Scots, until the use of a specially designed hydrometer put a stop to this 'minor racket'). The glass, iron, gas and tar, agricultural fermentation, the sugar and food industries are all dealt with by the historical-economic-sociological method. There is a useful chemical chronology from 1610 until 1856, and a glossary of dead chemical language, though some of the terms are still very much alive.

The book is a model of scholarly presentation, and it is fully documented and indexed. It is a handsome volume with 110 plates, including a reproduction of a coloured print of the old iron-works at Coalbrook Dale and a number of diagrams; and it is a pity that present-day costs necessitate a price of fifty shillings for the work.

W. L. Sumner

\section{THE FILM IN EDUCATION}

\section{The Film in Education}

By Dr. Andrew Buchanan. Pp. $256+25$ plates. (London: Phoenix House, Ltd., 1951.) 25s. net.

GVERYONE agrees that films can and should play E an important part in education. Yet practice and realization fall far below theory and ideal: progress has been slow. The reasons for this sorry state of affairs form a complex network. For example, there is a lack of the research which would guide both producers and users: we do not fully know how people look at pictures or diagrams, how they gather information from them, what features are truly significant. 'l'here are economic obstacles: visual material is expensive to produce, the market is small, the risks of failure great. Perhaps more important than such difficulties is the persisting traditionalism of teachers accustomed to rely on the written or spoken word, desensitized by their training to the appeal and meaning of visual presentations, uncertain of the best ways of using films in teaching, uninformed regarding sources of visual material, timid in their use of projection apparatus.

Dr. Andrew Buchanan has long been known as a producer of outstanding educational films, and he has done much to popularize their use in schools and universities. He has drawn on his experience to produce a book which will certainly become a standard work of reference. It should be noted, however, that he has imposed restrictions upon himself and that his book is far from being a comprehensive treatise on visual education. He makes little mention of film-strip, wall-chart, printed pictures, etc., nor does he deal with methods of displaying visualizations other than optical projection. There is very little fundamental discussion and few references to psychological or research data. In a word, the title well describes the book--but this particular restriction of necessity impoverishes the treatment.

Dr. Buchanan begins by speaking of the purposes, advantages and limitations of educational films, and goes on to the use of films for specialized purposes in medicine, science and art. He describes the development of such films in many countries and considers the contribution of Unesco. He devotes chapters to a detailed description of the planning, production and distribution of visual aids, taking account of the increasing part taken by the National Committee for Visual Aids. These chapters are of real value since this kind of information is essential to teachers who desire to collaborate fruitfully with professional producers. The author goes on to give advice on the method of handling projectors and suggests ways of conducting discussions with classes who have watched films, so that they may really learn from them. In addition to all this, he has gathered valuable material regarding the effects on children of watching entertainment films, and regarding the views currently held by teachers on the films they would like to have.

One of the most interesting sections of the book is that in which Dr. Buchanan shows with figures that it is almost impossible to produce films for the small British market without incurring a loss, and that the British tradition of parsimony in educational administration militates against success. It appears that the establishment of the semi-official Foundation for $V$ isual Aids has made the situation still worse by loading the scales still more against the producers.

Schools are by nature slow to change their ways or to adapt their practices to new conditions. Teachers are far less willing to adopt and employ new equipment or instruments than are workers in factories or offices; and, as was said earlier, our administrators have never learnt the lesson that education can be cheap or efficient but not both. In spite of all this, visual education has come to stay, and it will gradually affect practice and transform the process of instruction. Dr. Buchanan's book is a genuine contribution to the enlightenment of educators, and it may be warmly recommended to the attention of all who intend either to make or to use film. 